\title{
De-standardization of Family-Life Trajectories of Young Adults: A Cross-National Comparison Using Sequence Analysis
}

\author{
Dé-standardisation des trajectoires de vie familiale des jeunes \\ adultes: comparaison entre pays par analyse séquentielle
}

\author{
Cees H. Elzinga · Aart C. Liefbroer
}

Received: 24 October 2006/Accepted: 30 May 2007/Published online: 11 September 2007

(C) Springer Science+Business Media B.V. 2007

\begin{abstract}
We introduce a number of new methods based on sequence analysis to test hypotheses on the de-standardization of family-life trajectories in early adulthood, using Fertility and Family Survey data on 19 countries. Across cohorts, family-life trajectories of young adults have not become more turbulent. However, in most countries family-life trajectories of young adults have become less similar to one another and the variation in the types of family-trajectories has increased. Contrary to expectations, no clear differences in de-standardization were observed between countries characterized by a social-democratic welfare-state regime and countries characterized by either liberal or conservative welfare-state regimes.
\end{abstract}

Keywords Young adulthood · Family-life trajectories - De-standardization · Cross-national comparison $\cdot$ Sequence analysis

Résumé Nous introduisons une variété de nouvelles méthodes basées sur l'analyse séquentielle pour tester des hypothèses sur la dé-standardisation des trajectoires de vie familiale au début de l'âge adulte, en utilisant les données de l'enquête Fécondité et Famille dans 19 pays. D'une génération à l'autre, les trajectoires de vie familiale des jeunes adultes ne sont pas devenues plus "turbulentes". Toutefois, dans la-plupart des pays, ces trajectoires sont devenues de plus en plus dissemblables et diversifiées. A l'opposé des attentes, aucune différence claire en matière de dé-standardisation n'apparaît entre les pays caractérisés par un système de

C. H. Elzinga · A. C. Liefbroer

Department of Social Research Methodology, Vrije Universiteit, Amsterdam, The Netherlands

C. H. Elzinga

e-mail: ch.elzinga@fsw.vu.nl

A. C. Liefbroer $(\bowtie)$

Netherlands Interdisciplinary Demographical Institute, The Hague, The Netherlands

e-mail: liefbroer@nidi.nl 
protection sociale et de retraite de type social-démocrate et ceux caractérisés par un système de type libéral ou conservateur.

Mots-clés Début de l'âge adulte · Trajectoire de vie familiale .

Dé-standardisation · Comparaison entre pays · Analyse séquentielle

\section{Introduction}

In recent decades, most Western countries have witnessed large changes in the transition to adulthood. Young adults have postponed leaving their parental home (e.g., Goldscheider 1997), entry into marriage and entry into parenthood (e.g., Lesthaeghe and Willems 1999). Not only has the timing of these events changed; family formation has become, in many countries, a more extended sequence of events because some demographic phenomena (cohabitation, staying childless, living single, extra-marital parenthood) have become more accepted and practiced (Corijn and Klijzing 2001; Liefbroer and Goldscheider 2006). It has been suggested that these changes have led to an increased de-standardization and increased complexity of the transition to adulthood (e.g., Shanahan 2000). Within demography, Lesthaeghe and Van de Kaa's (Lesthaeghe 1995; Lesthaeghe and van de Kaa 1986; Van de Kaa 1987, 2001) description of these phenomena as constituting a 'Second Demographic Transition' (SDT) has sparked lively debate.

However, despite the broad interest that these changes have generated, a generally accepted methodology to assess their quantitative nature has not yet emerged. The reason for this is that the changes in the lives of young adults are not confined to just one demographic event like entering parenthood or to changes in the sequencing of a few events like entering marriage and finishing education. Instead, these changes affect life courses as a whole; from the set of available behavioural choices up to the sequencing and timing of complex chains of such choices. So, we need a methodology to study more general properties of life courses and the changes therein, rather than just the sequencing and timing of events. In recent decades, sequence analysis, driven by the technique of Optimal Matching, has emerged as a tool for analysing life-course trajectories (e.g., Abbott and Tsay 2000). However, the application of these methods in the social sciences has been widely and justly criticized (Dijkstra and Taris 1995; Settersten and Mayer 1997; Wu 2000; Elzinga 2003, 2005).

Against this background, the aim of this article is 2-fold. First, it aims to contribute to our understanding of the changes that occur during young adulthood by putting them in a cross-national perspective. Second, it introduces new methods that allow for the study of changes in demographic trajectories in a holistic fashion. More specifically, the methods introduced in this article will allow us to answer the following substantive research questions:

1. Have the demographic trajectories of young adults become more turbulent?

2. Have the demographic trajectories of young adults become less standardized?

3. Which types of demographic trajectories have become less common and which types of demographic trajectories have become more common? 
To answer these questions, we use data from 19 countries that participated in the Fertility and Family Surveys (FFS) programme. In what follows, we will first briefly review existing ideas about changes in family-life trajectories during young adulthood and formulate a number of hypotheses on this issue. Next, the data used will be described, followed by a brief discussion of methods to measure changes in family-life trajectories. After that, instead of separating the methods and results sections, we will combine the introduction of our methods used to measure aspects of young adults' trajectories and the results of these methods. Finally, the main methodological and substantive implications of our study will be discussed.

\section{Hypotheses on Changes in Family-life Trajectories}

Although opinions differ about the causes of the changes in the family-life trajectories of young adults (see Van de Kaa 1994; Lesthaeghe 1995 for overviews), few doubts exist that trajectories have become more diverse. Often, the concept of 'individualization' is used to summarize these changes in young adults' life courses (Arnett 2000; Beck and Beck-Gernsheim 1996; Buchmann 1989). However, Brückner and Mayer (2005) have suggested that individualization is a rather vague, sensitizing concept and that it is necessary to be more specific about the nature of these changes to arrive at testable hypotheses. They distinguish three more specific concepts that could be useful in arriving at such hypotheses. De-institutionalization refers to the process whereby the social and temporal organization of the life course becomes less guided by normative, legal or organizational rules. This concept is particularly useful if studying sequences of events in several different lifedomains. It implies that the order of events becomes less clear and that the likelihood of experiencing multiple events or combining multiple roles increases. De-standardization means 'that life states, events and their sequences can become experiences which either characterize an increasingly smaller part of the population or occur at more dispersed ages and with more dispersed durations' (Brückner and Mayer 2005, pp. 32-33). This concept is particularly useful if studying changes within specific life-domains, like family life. It implies that life courses become less similar and that the domination of specific types of life courses becomes weaker. Finally, differentiation is, according to Brückner and Mayer (2005, p. 33), the process whereby the number of distinct stages or states increases. If differentiation occurs in the family life course of young adults, it implies that the number of family-related states that young adults occupy increases.

Brückner and Mayer's overview offers a useful starting point to formulate hypotheses about the changes in family life in Europe. Differentiation implies that the number of family-related states during young adulthood has increased. The emphasis on the rise of new types of living arrangements suggests that this process may tap some of the important changes that are occurring in Western societies. But there is more than just an increase in distinct states: as partnerships are more easily established and dissolved, we observe an increase in distinct sub-patterns of familylife trajectories, such as intermittent spells of living single and living with a partner, whether married or unmarried. We use the term 'turbulence' (to be defined more 
precisely in Section 4.1) to capture this volatile and haphazard nature of the process of differentiation. Therefore, our first hypothesis is:

- Across cohorts, an increase in the turbulence of the family-life trajectories of young adults is to be expected (H1: turbulence hypothesis).

The concept of de-standardization implies that life courses of young adults become less similar to one another and that the domination of specific life courses becomes weaker. Although related, this concept includes two aspects that can be distinguished analytically. The first aspect is that life courses become less similar to one another. Applied to the family-life trajectories of young adults, this leads to the second hypothesis:

- Across cohorts, the family-life trajectories of young adults are expected to become more dissimilar to each other ( $\mathrm{H} 2$ : dissimilarity hypothesis).

The second aspect of the concept of de-standardization is the weakening domination of specific life courses. Applied to family-life trajectories during young adulthood this implies a weakening of the domination of trajectories characterized by early marriage and parenthood. Other types of trajectories, like a postponement trajectory characterized by late marriage and parenthood, or trajectories that include unmarried cohabitation, union dissolution and extra-marital parenthood should become more popular. As a result, the variation in family-life trajectories is bound to increase. Therefore, the third hypothesis to be tested is:

- Across cohorts, the domination of one specific type of family trajectory during young adulthood diminishes and a variety of different family-life trajectories becomes more prevalent (H3: variety hypothesis).

Until now, we have assumed that processes of de-standardization occur throughout the Western world. However, comparative studies suggest that large cross-national differences in the family-life trajectories of young adults exist (Corijn and Klijzing 2001; Liefbroer and Goldscheider 2006). Esping-Andersen's (1990, 1999) well-known typology of welfare-state regimes could be useful in generating hypotheses about this issue. Esping-Andersen (1990) originally distinguished three types of welfare-state regimes: social-democratic, conservative and liberal. In social-democratic welfare-state regimes, individuals rely predominantly on the State for social benefits in times of need. In liberal welfare-state regimes the market is the dominant provider of benefits, whereas in conservative regimes the family is viewed as the main provider of social benefits in times of need. For our purpose, the key distinction is between social-democratic regimes on the one hand and the two other regimes on the other. Within the social-democratic regime type, social benefits are provided by the State, largely irrespective of a person's social position. As a result, these benefits weaken the reliance of the individual on the family and thus facilitate autonomous behaviour. This is less the case in conservative and liberal welfare regimes. In these regimes, benefits are either targeted specifically to (traditional) families or are rather marginal, leading to a forced reliance on family. This suggests that the processes of de-standardization and differentiation are probably further advanced in countries that can be classified as social-democratic than in countries 
that can be classified as either liberal or conservative. In later work, a separate Mediterranean welfare-state regime, characterized by a very rudimentary welfare system and thus by extremely strong reliance on the family, has been distinguished (Esping-Andersen 1999; Gelissen 2001). It can be expected that processes of de-standardization and differentiation will not have advanced very far in these countries. An additional reason for low levels of de-standardization and differentiation in Mediterranean countries could be that the position of the Catholic (and Orthodox) Church, with its rather strict moral teaching on family matters, is still relatively strong in these countries. Finally, the typology remains silent about the position of Eastern European countries, at least before the fall of the Iron Curtain. On the one hand, one could argue that Communist ideology, with its emphasis on large-scale state-provision, would stimulate rather de-standardized and differentiated family-life trajectories. However, in practice most Communist states were characterized by strong normative constraints on individual behaviour, suggesting a relatively low level of de-standardization and differentiation. In addition, in some Communist countries, like Poland and Lithuania, the influence of the Catholic Church, with its strict teaching on family issues, was strong during the Communist era as well. Based on these considerations, it is possible to formulate a fourth hypothesis:

- Turbulence, dissimilarity and variety will be greatest in countries that can be classified as belonging to the social-democratic welfare-state regime, followed by countries characterized by liberal and conservative welfare-state regimes. Turbulence, dissimilarity and variety are lowest in countries characterized by a Mediterranean welfare-state regime and in former Communist countries (H4: welfare regime hypothesis).

\section{Methods}

\subsection{Data}

Data that allow the study of the transition to adulthood in a cross-national perspective are scarce. The dataset most widely used for this purpose is the Family and Fertility Survey, carried out in 25 countries between 1988 and 1999 by the national statistical offices under supervision of UN-ECE (see Fussel and Gauthier 2005; Corijn and Klijzing 2001 for examples). More information on the data collection and an evaluation of the quality of these data is provided by Festy and Prioux (2002). An advantage of this dataset is that it allows the comparison of a large number of Western countries, including some developed countries outside Europe. A disadvantage is the fact that relatively recent birth cohorts are not included, which makes it impossible to study change in the trajectories into adulthood for cohorts experiencing these transitions since the 1990s.

Data from six of the 25 countries were excluded for methodological or practical reasons. For some countries, information on the timing of some relevant events, like unmarried cohabitation, was missing, whereas for others the data were not available 
to us at the time of the analysis. Thus, we included data from 19 countries, 12 of which already belonged to the Western world before the end of the Cold War, and 7 that were under a Communist regime dominated by the former USSR. In order to study trajectories that cover most of young adulthood, we selected respondents who were 30 years or older at the date of interview. In addition, we selected women only. Data on men are available for a smaller number of countries. In addition, family formation events generally take place earlier in the life course of females and we do not want evidence on de-standardization to be blurred by gender differences in timing. For each country, four birth cohorts (1945-1949, 1950-1954, 1955-1959 and 1960-1964) were defined. Since the variation in the year in which the data were collected, we could construct datasets covering all four cohorts for 11 countries only. For the other eight countries, we have data on three consecutive cohorts. The final sample sizes and cohortal fractions are shown in Table 1.

In all countries, full event histories on childbearing and union formation were collected. Using these histories, a respondent's family status for each month between the ages of 18 and 30 was calculated, leading to a trajectory of 144 consecutive family-life statuses. In constructing these trajectories, we distinguished six family formation states, three of which pertain to the spell before entering parenthood: living single (S), living together unmarried (U) and living together

Table 1 Number of respondents per country and proportion of respondents per cohort

\begin{tabular}{|c|c|c|c|c|c|}
\hline & 1945-1949 & 1950-1954 & 1955-1959 & 1960-1964 & Total $N$ \\
\hline Austria & 0.216 & 0.223 & 0.260 & 0.301 & 2,499 \\
\hline Canada & 0.189 & 0.222 & 0.267 & 0.322 & 2,370 \\
\hline Czech Republic & - & 0.162 & 0.422 & 0.415 & 708 \\
\hline Estonia & 0.252 & 0.262 & 0.254 & 0.231 & 1,227 \\
\hline Finland & 0.343 & 0.325 & 0.332 & - & 2,263 \\
\hline France & 0.201 & 0.258 & 0.307 & 0.234 & 1,915 \\
\hline Hungary & - & 0.313 & 0.447 & 0.240 & 1,953 \\
\hline Italy & 0.192 & 0.258 & 0.267 & 0.283 & 2,895 \\
\hline Latvia & 0.188 & 0.261 & 0.280 & 0.272 & 1,738 \\
\hline Lithuania & 0.198 & 0.239 & 0.261 & 0.302 & 1,704 \\
\hline Netherlands & - & 0.362 & 0.383 & 0.255 & 2,590 \\
\hline New Zealand & 0.207 & 0.245 & 0.287 & 0.262 & 1,758 \\
\hline Norway & 0.293 & 0.336 & 0.371 & - & 1,865 \\
\hline Poland & 0.295 & 0.360 & 0.344 & - & 2,176 \\
\hline Portugal & 0.127 & 0.270 & 0.253 & 0.350 & 2,594 \\
\hline Slovenia & - & 0.301 & 0.344 & 0.355 & 1,593 \\
\hline Spain & 0.155 & 0.218 & 0.295 & 0.332 & 2,249 \\
\hline Sweden & 0.335 & 0.323 & 0.341 & - & 1,989 \\
\hline \multirow[t]{2}{*}{ USA } & - & 0.292 & 0.354 & 0.354 & 6,066 \\
\hline & & & & & 4,2140 \\
\hline
\end{tabular}

For some countries, there are no data for either the first or the last cohort. Countries are ordered lexicographically 
married (M). Each of these codes can be extended with a $\mathrm{C}$, meaning that the woman is living together with at least one child as well. So, a life course could look like the sequence $\mathrm{S} / 20 \mathrm{M} / 30 \mathrm{MC} / 94$, meaning that the woman lived single for 20 months, then lived together with a husband for 30 months and finally gave birth to her first child while still living together with a husband; the last status remaining unchanged, at least for the remaining 94 months.

\subsection{Methods of Studying Sequences and Trajectories}

To test the hypotheses formulated in Section 2, a methodology and quantification is needed that focus on sequences as a whole. A number of such methods exist and have been applied to demographic sequences. For example, a very simple method to study (change in) standardization is to count the (change in the) number of distinct trajectories or to measure changes in classification of trajectories. Examples of such methods can be found in e.g., Liefbroer and De Jong Gierveld (1995), Mouw (2005) and $\mathrm{Wu}$ and $\mathrm{Li}$ (2005). Of course, such simple methods cannot take differences in duration into account, simply because there are too many. A classification method that explicitly uses durations of a limited number of (possibly overlapping) properties is the monothetic division algorithm, a top-down hierarchical clustering technique proposed by Piccarreta (1998) that was applied in demography by Billari and Piccarreta (2005) and Mouw (2005). However, as is the problem with most hierarchical methods, it is very difficult to specify the overall loss-function minimized. Optimal Matching (Abbott 1984; Abbott and Tsay 2000) fully exploits the sequential structure of lifecourse trajectories. However, the metric representation it generates is hard to interpret in social science applications, it does not handle durations in a straightforward and meaningful way and it is unclear how to define similarity from the distances calculated (e.g., Dijkstra and Taris 1995; Wu 2000; Elzinga 2003, 2005).

As this succinct overview makes clear, existing methods to study trajectories suffer from serious limitations. In this article, we will introduce a number of alternative methods that make full use of the available information on trajectories and measure the similarities and dissimilarities between trajectories in a statistically and theoretically appealing way. For each of the three aspects of de-standardization (turbulence, dissimilarity and variety), one specific method will be proposed. These three methods will be introduced and applied in separate sections. Each section has the same structure. First, the respective method will be introduced in a rather informal way. Subsequently, the method will be applied in order to test our hypotheses about trends in de-standardization of family-life trajectories.

\section{Turbulence of Family-life Trajectories}

\subsection{Developing a Measure of Turbulence}

Our first hypothesis states that the level of turbulence in family-life trajectories increases across cohorts. This hypothesis mirrors the idea, to be found in e.g., 
Shanahan (2000), Mills (2004), Brüderl (2004) and Brückner and Mayer (2005), that de-standardization comes with increasingly turbulent sequences, 'turbulence' implying an increasing number of transitions and/or an increasing number of distinct states and/or increasing variation in the timing/duration of events. However, to allow a formal test of our first hypothesis, a more precise and quantified definition of turbulence in categorical time series is needed.

The concept of 'turbulence' is well known in hydrodynamics, where it refers to a property of flow. A flow is turbulent if its speed and direction are unstable, i.e., changes rapidly and irregularly. Categorical time series like life courses also consist of flows of events or states in time. We will consider series that have many distinct states and many state changes as being more turbulent than series with fewer distinct states and/or fewer state changes. This implies that the substantive meaning of the various states involved does not play a role in determining the amount of turbulence of the categorical time series. So, restricting ourselves to the life course domain, we consider the series "S, M, MC" as being equally turbulent as the trajectory "U, UC, SC" since they have the same number of (distinct) states. So, our concept of turbulence will pertain to the general structure of the time series and not to the degree in which a particular series departs from what is, or is thought to be, the 'standard trajectory'. This ensures that the concept of turbulence will equally apply to time series from different societies or different epochs. As we mentioned before, turbulence not only pertains to the number and kinds of events occurring in the trajectory. The time spent in the various states and the variation of these durations will also play a role. However, we will first pay attention to the ways in which the states as such determine turbulence. Once we have precisely defined this, we will return to the durations of the states and discuss how to incorporate these too.

To start with, let us consider three different family-life trajectories:

$$
x=\mathrm{S}, \mathrm{U}, \mathrm{M}, \mathrm{MC} \quad y=\mathrm{S}, \mathrm{U}, \mathrm{S}, \mathrm{M} \quad z=\mathrm{S}, \mathrm{U}, \mathrm{M}, \mathrm{S} .
$$

Each of these series consists of four events. However, more different events occur in $x$ than in $y$ or $z$, since in $y$ and $z$, the state $\mathrm{S}$ repeats. Therefore, we consider $x$ to be more turbulent than either of the trajectories $y$ or $z$. But $y$ and $z$ have the same number of events and the same number of distinct events. Still, we do not consider these two trajectories to be equally turbulent because after $\mathrm{S}$ occurred, it takes more events in $z$ to return to $S$ than in $y$. Therefore, we consider $z$ to be more turbulent than $y$ : more different things happen in $z$ before $\mathrm{S}$ is encountered again. More generally, we will say that turbulence increases with an increase in the average number of states before the next repetition of a state is encountered. If such a repetition is never encountered, as in sequence $x$, turbulence is maximal given the length, i.e., the number of states, of the sequence. However, determining this average number is far from straightforward. Fortunately, the average number of states before a next repetition is encountered is monotone with the number of distinct subsequences and the latter quantity appears to be fairly easy to determine. So, we operationalize turbulence as the number of distinct subsequences and therefore concisely discuss the formal concepts of 'sequence' and 'subsequence' first. 
Let $A$ denote an alphabet, i.e., a set of states. Sequences $x$ are constructed by taking copies from the elements of $A$ and concatenating the copies taken: the sequence $x=x_{1} x_{2} \ldots x_{k}$ with $x_{i} \in A$ is said to be of length $k$. A sequence $u$ is said to be a subsequence of $x$ if all the states of $u$ appear in $x$ and in the same order, and we write $u \in x$ to denote this fact. So, the sequence $u=\mathrm{S}, \mathrm{M}$ is a subsequence of $x, y$ and $z$ and the reader notes that it is embedded twice in $y$. We will write $\phi(x)$ for the number of distinct subsequences of a sequence $x$. A special subsequence is the empty subsequence $\lambda$, which is a subsequence of every sequence. Note that, because of the definition of subsequence, every sequence is a subsequence of itself. Hence, $\phi(\lambda)=1$ and $\phi(x) \geq 1$. So defined, it is readily verified by listing and enumerating that, for the above example sequences, we have ${ }^{1}$

$$
\phi(x)=16>\phi(z)=15>\phi(y)=14,
$$

and indeed, the ordering of the $\phi$-numbers reflects the ordering of the turbulences as discussed. The increase of $\phi(x)$ with increasing length of $x$ may be more than exponential. To avoid excessively large figures, Elzinga (2006) proposes to use the quantity

$$
0 \leq T(x)=\log _{2} \phi(x),
$$

as a measure of turbulence of sequences without durations. Effectively, this yields $T(x)=4>T(z)=3.91>T(y)=3.81$, which still reflects the ordering discussed above.

The above measure does not yet take the duration of each subsequence into account. To include duration into our concept of turbulence, some additional decisions have to be taken. We will consider a family-life trajectory of the form $\mathrm{S} / 10 \mathrm{U} / 2 \mathrm{M} / 132$ as being less turbulent than the trajectory S/48 U/48 M/48; in the first sequence, time was predominantly spent in the state $M$ and only brief periods were spent in other states, whereas in the second sequence, equal amounts of time were spent in all states. Now observe that the variance of the times spent in the states is quite large in the first, less turbulent sequence whereas in the second, more turbulent sequence, this variance equals 0 . So turbulence increases with a decrease in the variance of the times spent in the states. Let $s_{t}^{2}$ denote the variance of the state-durations and $s_{t, \max }^{2}$ the maximum of that variance given the total duration of the sequence. Then Elzinga (2006) proposes to use

$$
T(x)=\log _{2}\left(\phi(x) \cdot \frac{s_{t, \max }^{2}(x)+1}{s_{t}^{2}(x)+1}\right),
$$

with $s_{t \text { max }}^{2}=(n-1)(1-\bar{t})^{2}$ and $\bar{t}$ denoting the average of the state-durations of the sequence $x$, as a measure of turbulence that takes the durations into account. As

\footnotetext{
${ }^{1}$ For many reasons it is convenient to consider the empty sequence $\lambda$ as being a subsequence of every conceivable sequence. With this in mind, a paper-and-pencil exercise will convince the reader that the number of distinct subsequences of S U S M indeed equals 14. However, calculating the number of subsequences for longer sequences is very time-consuming. A description of a simple algorithm to determine the number $\phi(x)$ of distinct subsequences of a sequence $x$ is available from the first author on request.
} 
specified in (2), $T(x)$ will increase with decreasing variance of the durations of the states and it will not be sensitive to the specific time scale used. Hence, with $T(x)$ as defined in (2), the sequence property of turbulence is quantified such that the sequencing of the states and the variance of their durations is taken into account.

\subsection{Empirical Results on Turbulence}

The turbulence measure defined in (2) can be used to calculate the average turbulence of the family-life trajectories of women, per country and per cohort, and to test our hypothesis that the turbulence will increase across cohorts. The results are presented in Table 2. ${ }^{2}$ It turns out that the countries can be divided into three groups, based on the cross-cohort trends in average turbulence. In ten countries, average turbulence is more or less stable across cohorts. Most of these countries are formerly Communist ones, but this group also includes Spain, The Netherlands and Sweden. In seven countries, an increase in average turbulence is observed. These countries are Canada, Austria, Norway, Finland, USA, France and New Zealand. Most surprisingly, in two countries (Portugal and Italy) a decrease in average turbulence across cohorts is observed. Therefore, no clear support for our first hypothesis is found. Although individual family-life trajectories are becoming more turbulent in a minority of countries, in many countries no increase in turbulence or even a decrease in turbulence is observed.

Our fourth hypothesis suggests that turbulence will be highest in countries that can be classified as belonging to the social-democratic welfare-state regime, followed by countries characterized by liberal and conservative welfare-state regimes, and with Mediterranean and former Communist countries having the lowest levels of turbulence. The results in Table 2 show that the ordering of countries partly conforms to expectations: there seems to be a divide between the Mediterranean and former Communist countries on the one hand and the other countries on the other. However, no clear difference is evident between countries belonging to the social-democratic welfare regime and those belonging to liberal and conservative regimes.

\section{Similarity of Family-life Trajectories}

\subsection{Developing a Measure of Similarity}

The second hypothesis states that, across cohorts, the family-life trajectories of women become more dissimilar to one another. Perfect similarity would imply that, in each cohort and in each country, only one sequence of states suffices to represent the family-life trajectories of all women. Of course, this sequence of states could be

\footnotetext{
${ }^{2}$ In this article we use bootstrapped confidence intervals of a type that is generally known as $\mathrm{BC}_{\mathrm{a}}$ : "biascorrected accelerated". An explanation of this particular type of confidence intervals is beyond the scope and purpose of the present article; for a discussion of $\mathrm{BC}_{\mathrm{a}}$-intervals, the interested reader is referred to Efron and Tibshirani (1994) or Davison and Hinkley (1997).
} 
Table 2 Average turbulence $\bar{T}(x)$ per country per cohort

\begin{tabular}{|c|c|c|c|c|}
\hline & 1945-1949 & 1950-1954 & 1955-1959 & 1960-1964 \\
\hline Portugal & 4.602 & 4.529 & 4.289 & 4.263 \\
\hline Italy & 4.701 & 4.663 & 4.353 & 4.371 \\
\hline Poland & 4.697 & 4.687 & 4.593 & \\
\hline Spain & 4.613 & 4.897 & 4.924 & 4.698 \\
\hline Hungary & & 4.819 & 4.848 & 4.917 \\
\hline Czech Republic & & 4.939 & 4.893 & 5.006 \\
\hline Slovenia & & 4.812 & 4.733 & 5.007 \\
\hline Lithuania & 5.007 & 4.886 & 5.151 & 5.057 \\
\hline Latvia & 5.158 & 5.226 & 5.405 & 5.246 \\
\hline Canada & 4.725 & 4.993 & 5.273 & $\mathbf{5 . 4 3 7}$ \\
\hline Austria & 5.007 & 5.133 & 5.217 & 5.457 \\
\hline Norway & 5.024 & 5.148 & 5.511 & \\
\hline Finland & 4.902 & 5.352 & 5.527 & \\
\hline Estonia & 5.448 & 5.617 & 5.804 & 5.549 \\
\hline USA & & 5.264 & 5.414 & 5.685 \\
\hline Netherlands & & 5.681 & 5.879 & 5.827 \\
\hline Sweden & 5.823 & 5.828 & 5.879 & \\
\hline France & 5.028 & 5.175 & 5.513 & 5.896 \\
\hline New Zealand & 5.450 & 5.384 & 5.817 & 6.142 \\
\hline
\end{tabular}

Boldface is used to indicate that the change over cohorts is significant as evidenced by non-overlapping $90 \%$ confidence intervals

Countries are ordered according to the average turbulence of the last cohort available

different for different cohorts and different countries. Evidently, this is not what we find. In our samples, the number of observed sequences varies from 16 amongst Portuguese women born between 1945 and 1949 to 305 amongst US women born between 1960 and 1964. The amount of diversity in family-life trajectories can be illustrated by comparing the US and Italy. The same three sequences that allow for classification of 90\% of all Italian women born between 1945 and 1949, represent less than 35\% of US women born between 1960 and 1964. Interestingly, in both countries the highest fraction for both cohorts pertains to the 'traditional' S M MC sequence. However, this proportion is much bigger in Italy (.70) than in the USA (.20).

There are several ways to quantify dissimilarity of trajectories. The most simple way would be to merely count the number of distinct trajectories occurring in a cohort (e.g., Wu and Li 2005) and to observe if and how this number changes over time and/or across cohorts. However, a major drawback of this number is its insensitivity to the prevalence of the trajectories counted. A measure sensitive to prevalence is the entropy of the distribution of trajectories. ${ }^{3}$ Indeed, Brüderl (2004)

\footnotetext{
${ }^{3}$ For an introduction into the properties of entropy and related measures, the reader is referred to Cover and Thomas (1991).
} 
used the entropy measure to show that the variation of the distribution of trajectoryclasses increases over time. Also, Fussell (2005) used entropy to demonstrate variation in early adult life courses. Unfortunately, by using entropy, one ignores an important aspect of variability in sequences: the durations of the states within sequences. Ideally, one would want a method to measure similarity of trajectories that can handle durations. However, handling duration is complex and how to deal with its added complexity is one of the central debates in life-course research (Abott 1984; Abbott and Tsay 2000; Settersten and Mayer 1997; Wu 2000; Elzinga 2003; Billari and Piccarreta 2005; Mouw 2005). Therefore, before presenting our measure of dissimilarity of family-life trajectories, some comments on the issue of handling duration are in order.

In the present context, durations can be defined as a vector of quantities. In principle, the way to deal with variation between vectors is clear-cut: we consider their distance or, if the vectors are on the surface of a unit-sphere, their similarity or angle. If there is little variation amongst a set of vectors, their average distance or angle will be small and all angles or distances will vanish if all the vectors are identical. So, for the pair of sequences 'S/24 M/60 MC/60' and 'S/56 M/12 MC/76', we could calculate the squared Euclidean distance between the duration vectors $(24,60,60)$ and $(56,12,76)$ as the sum of the squared differences $(24-56)^{2}+\cdots=$ 2584. Thus, the computation of Euclidean distance between such duration-vectors amounts to comparing coordinate differences pertaining to the time spent in corresponding states. However, in sequence analysis, a number of additional problems arise if one wants to take the duration of states into account. Consider, for instance, the pair of sequences 'S/24 M/60 MC/60' and 'U/56 S/12 MC/76'. In this case, it is not so clear how to compare the vectors because most duration-differences pertain to different states: the quantity $(24-56)^{2}$ is the squared difference between time spent living single and time spent cohabitating. So, it may seem desirable to consider vectors with as many coordinates as we have distinct states, each coordinate representing the time spent in a fixed state. This would certainly ensure that we would only compare durations of the same state when calculating distances. But this procedure would still leave us with a problem. Consider the pair ' $\mathrm{S} / 72 \mathrm{U} /$ 72 ' and 'S/36 U/36 S/36 U/36'. The distance between the duration vectors would be zero since in both life courses equal amounts of time are spent in equal states and we would have to conclude that we have no variation in durations for this small set of life courses.

Apparently, the problem is that it does not make sense to look at durations without taking the sequencing of states into account at the same time. So, we need a metric to compare sequences that takes the ordering of the states and their duration into account simultaneously. What such a metric should look like for social science categorical time series is a much debated subject (e.g., Settersten and Mayer 1997; Wu 2000; Elzinga 2003; Billari and Piccarreta 2005; Mouw 2005). In the social sciences, Optimal Matching (OM), introduced by Abbott (1984; Abbott and Tsay 2000 ) is the most popular metric to evaluate the level of similarity between categorical time series, but its usefulness is subject to much debate. In particular, two fundamental criticisms have been raised. The first of these criticisms boils down to the fact that the metric of $\mathrm{OM}$ implies a geometry of sequence representation that 
has no interpretation in the social sciences. The second criticism amounts to saying that $\mathrm{OM}$ does not handle durations in a logical way. Still, OM-distances seem to work quite well in practice: sequences that are quite similar are assigned small OMdistances and sequences that are very different are assigned large differences. Indeed, despite the criticisms that have been raised, OM has been successfully applied to the analysis of partnership histories (Brüderl 2004) and labour market entry sequences (Brüderl and Scherer 2006; Brzinsky-Fay 2006) for example.

Recently, Elzinga (2005) suggested a quite different metric that has a natural interpretation and handles durations in a more consistent way. We concisely discuss it here since we will use it to handle the problem of dealing with dissimilarity in a way that includes variability of timing. If $u \in x$ and $u \in y$, we say that $u$ is a common subsequence of $x$ and $y$ and we write $u \in S(x, y)$ where $S(x, y)$ denotes the set of common subsequences of the pair $(x, y)$. A particular subsequence may be embedded more than once in $x$ : for example, if $x=\mathrm{S} \mathrm{U} M \mathrm{~S} \mathrm{U}$, the subsequence $u=\mathrm{S} \mathrm{U}$ is embedded three times in $x$. We then write $|x|_{u}=3$. We now define the number of matching subsequences of $x$ and $y$ as

$$
m(x, y)=\sum_{u \in S(x, y)}|x|_{u} \cdot|y|_{u} .
$$

Thus, $m(x, y)$ depends upon the number of common subsequences of $x$ and $y$, weighted by the frequency of occurrence of these subsequences in both $x$ and $y$. The distance $d_{m}(x, y)$ is now defined as the number of non-common subsequences of both $x$ and $y$, weighted by the frequency with which they occur in either sequence:

$$
0 \leq d_{m}(x, y)=m(x, x)+m(y, y)-2 m(x, y) .
$$

This metric implies a mapping of each sequence $x$ to a vector $\mathbf{x}$ such that $\sqrt{m(x, x)}$ corresponds to the length of that vector and such that $\sqrt{d_{m}(x, y)}$ corresponds to the Euclidean distance between the vectors $\mathbf{x}$ and $\mathbf{y}$. The quantity

$$
0 \leq s_{m}(x, y)=\frac{m(x, y)}{\sqrt{m(x, x) \cdot m(y, y)}} \leq 1,
$$

corresponds to (the cosine of) the angle between the vectors. If $x$ and $y$ have no common subsequences, distance is maximal and $m(x, y)=0$, and if $x=y$, all subsequences of $x$ occur equally often in $y$ hence $m(x, x)=m(y, y)=m(x, y)$ in which case $s_{m}(x, y)=1$. Therefore, the natural interpretation of the quantity $s_{m}(x, y)$ is that of the similarity between the sequences $x$ and $y$. The metric as defined in (4) is easily extended to handle durations in a straightforward way, essentially by replacing each product $|x|_{u} \cdot|y|_{u}$ as appearing in (3) by a sum of products of associated durations. We will not further dwell upon these technicalities; for details and algorithms, the reader is referred to Elzinga (2005).

With the similarity-index as defined in (5), we have a way of quantifying the degree of standardization while taking differences in timing or duration into account. The degree of standardization within a set of sequences can be defined as the average of the similarities between all pairs of sequences. If the average 
similarity is close to 1 , standardization is high and if close to 0 , standardization is low. So quantified, standardizations of different sets of sequences are directly comparable since the similarity-index is unit-free.

\subsection{Empirical Results on Similarity}

To test the hypothesis that the family-life trajectories of young adults become less similar across cohorts, we calculated the average similarity between the sequences from every cohort and each country using the similarity index defined in (5). The results are presented in Table 3. Substantively, a number of interesting observations can be made on this table. In line with the similarity hypothesis, average similarity is decreasing over time in the vast majority of countries. We calculated bootstrapped $90 \%$-confidence intervals for the figures in Table 3; it appears that only in fourformerly Communist - countries this increase is not significant. These countries are Poland, Lithuania, the Czech Republic and Latvia. In all other countries, the similarity of family-life trajectories has decreased if one compares women born between 1945 and 1949 with women born between 1960 and 1964. Therefore, in the great majority of countries, the similarity hypothesis is supported.

Table 3 Average similarity per cohort per country

\begin{tabular}{|c|c|c|c|c|}
\hline & 1945-1949 & 1950-1954 & 1955-1959 & 1960-1964 \\
\hline Poland $^{\mathrm{a}}$ & 0.594 & 0.589 & 0.574 & \\
\hline Lithuania $^{\mathrm{a}}$ & 0.596 & 0.567 & 0.536 & 0.553 \\
\hline Czech Republic $^{\mathrm{a}}$ & & 0.501 & 0.505 & 0.526 \\
\hline Spain & 0.645 & 0.646 & 0.596 & 0.499 \\
\hline Italy & 0.621 & 0.593 & 0.496 & 0.497 \\
\hline Hungary & & 0.522 & 0.506 & 0.434 \\
\hline Latvia $^{\mathrm{a}}$ & 0.462 & 0.445 & 0.461 & 0.425 \\
\hline Portugal & 0.491 & 0.486 & 0.459 & 0.418 \\
\hline Slovenia & & 0.522 & 0.436 & 0.380 \\
\hline Netherlands & & 0.475 & 0.384 & 0.351 \\
\hline Finland & 0.437 & 0.372 & 0.323 & \\
\hline Norway & 0.517 & 0.425 & 0.311 & \\
\hline Estonia & 0.326 & 0.277 & 0.278 & 0.263 \\
\hline Austria & 0.405 & 0.348 & 0.282 & 0.255 \\
\hline Canada & 0.357 & 0.301 & 0.279 & 0.247 \\
\hline New Zealand & 0.459 & 0.337 & 0.268 & 0.218 \\
\hline France & 0.413 & 0.370 & 0.254 & 0.218 \\
\hline Sweden & 0.258 & 0.234 & 0.226 & \\
\hline USA & & 0.251 & 0.222 & 0.204 \\
\hline
\end{tabular}

\footnotetext{
${ }^{a}$ Differences between cohorts are not significant

Countries are ordered according to the similarity within the last cohort available
} 
Our fourth hypothesis suggests that the level of similarity of family-life trajectories of young adults differs between countries belonging to different welfarestate regimes. This hypothesis is partially confirmed. Family-life trajectories of young adult women are clearly less similar to each other in countries belonging to the social-democratic, liberal and conservative welfare-state regimes than in either Mediterranean countries or in former Communist countries. At the same time, no differences are observed in the level of similarity of family-life trajectories between countries belonging to the social-democratic, liberal and conservative welfare-state regimes. Most striking is that the Scandinavian countries do not clearly stand out with regard to their level of similarity. Although Sweden is almost top of the board, the similarity of family-life trajectories in Finland and Norway is not very high compared to other Western countries. The position of the USA may be one of the most surprising results of this analysis. Of all countries included in this study, family-life trajectories of US female young adults are least similar to one another.

\section{Variation in Types of Family-life Trajectories}

\subsection{Developing a Measure of Variation}

In this section we will focus on our third hypotheses which states that, over time, there will be increasing variation in the types of family-life trajectories. Evidently, testing this hypothesis requires a typology or classification of family-life trajectories that makes sense both theoretically and empirically, a method to assign the trajectories of each respondent to one of the types, and a method to calculate the level of variation in types. Each of these issues will be discussed in turn.

An important distinction between different strategies for assigning trajectories to classes is whether the strategy uses an inductive approach or rather a deductive one. One inductive method for obtaining such a classification is to apply a divisive or an agglomerative algorithm directly to the sequences. Indeed, Piccarreta (1998; Billari and Piccarreta 2005) proposed a divisive algorithm that is applicable to sequence data and the method was recently applied by Mouw (2005) to analyze transition sequences of young American adults. However, the problem with such hierarchical methods is that the objective function minimized, i.e., the definition of cluster or class, changes at each and every step of the algorithm. Another inductive approach for constructing a typology would be to calculate distances between the family-life trajectories according to Eq. 4 and use the resulting distance matrix to separate the trajectories into disjoined sets through some method of cluster analysis. This method has a number of drawbacks. First, it would prove to be quite some computational challenge: we have 42,140 trajectories, implying some $8 \times 10^{8}$ distances to use in a single cluster analysis. Even if the sheer size of this task were not a problem, we would have to choose a particular cluster-definition and an algorithm to evaluate the corresponding loss-function. Furthermore, it would be difficult to decide on the number of clusters or classes to separate, although there are some stopping rules generally believed to generate satisfying results (Milligan and Cooper 1985; Tibshirani et al. 2002). Finally, if we have to cluster per country, it is quite likely 
that the resulting classification will differ from country to country, making crossnational comparisons problematic.

Due to these objections to inductive methods, we prefer a more deductive method in which we define a typology of family-life trajectories, and decide on a method for assigning each empirically observed trajectory to one of these predefined types. In practice, we added a set of template-trajectories $\left\{y_{k}\right\}$ (to be discussed shortly) to our data, the observed trajectories $\left\{x_{i}\right\}$, and assigned each of the observed trajectories to the template-trajectory to which it is closest, the distance being measured through Eq. 4. This procedure generates a classification $C=\left\{C_{j}\right\}$ consisting of $k$ classes, defined by

$$
x_{j} \in C_{i} \Leftrightarrow d\left(x_{j}, y_{i}\right)=\min _{k}\left\{d\left(x_{j}, y_{k}\right)\right\}
$$

To arrive at a measure of variation, we write $p_{j}$ for the proportion of observed sequences assigned to class $C_{j}$. If, for a particular cohort or country, there is no variation in the type of family-life trajectory, implying that all trajectories belong to one and the same type, then $p_{j}=1$ for one class and $p_{i}=0$ for all other classes. If, on the other hand, variation of types is maximal, this means that all classes must have been assigned an equal number of trajectories and hence that $p_{j}=1 / k$, where $k$ denotes the number of classes. A number that measures the amount of variation or uncertainty of the distribution $\left\{p_{j}\right\}$ is the entropy $H_{C}$, defined as

$$
0 \leq H_{C}=-\sum_{i}^{k} p_{i} \log \left(p_{i}\right) \leq \log (k) .
$$

Since the maximum of $H_{\mathrm{C}}$ depends upon the number of classes $k$, we prefer to use the relative entropy

$$
0 \leq h=H_{\mathrm{C}} / \log (k) \leq 1,
$$

which reaches its upper bound of 1 in case of maximal variation, i.e., when the distribution $\left\{p_{j}\right\}$ is uniform. Formulated in terms of relative entropy, our third hypothesis implies that relative entropy $h$ should increase across cohorts.

Of course, the proposed approach makes sense if, and only if, the set of templates $\left\{y_{j}\right\}$ is well chosen. A set of templates can be chosen both on substantive and on empirical grounds. In this case, we decided to develop a set of $k=7$ templates that jointly reflect many of the changes that are part of the Second Demographic Transition. These template-trajectories are presented in Table 4.

The first two templates, labelled Traditional Early Motherhood (TEM) and Traditional Late Motherhood (TLM), represent traditional modes of family formation based on the sequence S M MC, the difference between the two being that in TLM, motherhood is postponed. The second pair of templates represents non-traditional family formation in the sense that in both templates, a substantial spell of cohabitation takes place. In Modern Late Motherhood (MLM), cohabitation is transformed into marriage before entering motherhood, whereas in Alternative Late Motherhood (ALM) motherhood is entered while the couple is cohabiting unmarried. The third pair of templates was constructed around the dissolution of 
Table 4 Template life courses and their acronyms

\begin{tabular}{|c|c|c|c|c|c|}
\hline Description & Acronym & & & & \\
\hline Traditional early motherhood & TEM & $\mathrm{S} / 48$ & $\mathrm{M} / 24$ & $\mathrm{MC} / 72$ & \\
\hline Traditional late motherhood & TLM & $\mathrm{S} / 60$ & $\mathrm{M} / 60$ & $\mathrm{MC} / 24$ & \\
\hline Modern late motherhood & MLM & $\mathrm{S} / 60$ & $\mathrm{U} / 24$ & $\mathrm{M} / 36$ & $\mathrm{MC} / 24$ \\
\hline Alternative late motherhood & ALM & $\mathrm{S} / 60$ & $\mathrm{U} / 60$ & $\mathrm{UC} / 24$ & \\
\hline Sequential cohabitation & $\mathrm{SCO}$ & $\mathrm{S} / 48$ & $\mathrm{U} / 24$ & $\mathrm{~S} / 12$ & $\mathrm{U} / 60$ \\
\hline Parenthood dissolution & PDI & $\mathrm{S} / 48$ & $\mathrm{M} / 24$ & $\mathrm{MC} / 36$ & $\mathrm{SC} / 36$ \\
\hline Singlehood & SIN & $\mathrm{S} / 144$ & & & \\
\hline
\end{tabular}

partnerships. The first one of these, labelled Sequential Cohabitation (SCO) focusses on the dissolution of a first, relatively brief spell of unmarried cohabitation, whereas the second one, labelled Parenthood Dissolution (PDI), represents the breaking up of the traditionally formed family. Finally, we added a template in which women do not start their family formation process during young adulthood. This template is called Singlehood (SIN), and is represented by a continuous spell of 144 months in the state of singlehood.

To empirically check for the relevance, usefulness and sufficiency of this set of templates, we ran K-means cluster analysis with the minimal distance criterion (Hartigan 1975) per country and cohort, with the number of clusters varying from three to ten. In all countries, using the Calinski-Harabasz coefficient as a stopping rule, five to eight clusters that closely resemble the templates as defined in Table 4 were found.

\subsection{Empirical Results on Variation}

Based on the method described in Section 6.1, we assigned each individual trajectory to one of the templates defined in Table 4. The results of this analysis consist of a vast amount of data, since we have a total of 67 cohorts. Since our main interest is in cross-cohort changes, we will present the proportion of respondents that are assigned to each template for the oldest and the youngest cohort in each country only. The results are presented in Table 5.

A first observation to be made from Table 5 is that TEM, implying early marriage, shortly afterwards followed by motherhood, is by far the most popular template amongst the oldest birth cohorts in almost all countries. Estonia and Sweden are the only exceptions. In eight countries, even the majority of the oldest cohort is classified in this template. Across cohorts, however, TEM declines in popularity in all countries, except in Poland, the Czech Republic and Estonia. In six countries, TEM even loses its position as the most popular template. In Norway, Austria, the Netherlands, Finland and New Zealand, the position of most popular template is occupied by MLM, implying a postponement of parenthood and the introduction of a spell of premarital cohabitation. The TLM-template, implying postponed marriage and motherhood, but no cohabitation, is particularly popular, 
Table 5 Proportion of respondents who are assigned to specific templates, by country and birth cohort

\begin{tabular}{|c|c|c|c|c|c|c|c|}
\hline Country, cohort & TEM & TLM & MLM & ALM & $\mathrm{SCO}$ & PDI & SIN \\
\hline Poland, 1945-1949 & .62 & .15 & .01 & .01 & .00 & .08 & .12 \\
\hline Poland, 1955-1959 & .61 & .14 & .01 & .02 & .01 & .12 & .11 \\
\hline Hungary, 1950-1954 & .61 & .11 & .04 & .02 & .01 & .15 & .07 \\
\hline Hungary, 1960-1964 & .57 & .09 & .07 & .04 & .04 & .12 & .07 \\
\hline Lithuania, 1945-1949 & .58 & .17 & .04 & .01 & .01 & .09 & .11 \\
\hline Lithuania, 1960-1964 & .54 & .13 & .06 & .03 & .02 & .11 & .11 \\
\hline Czech Republic, 1950-1954 & .48 & .16 & .12 & .03 & .01 & .13 & .07 \\
\hline Czech Republic, 1960-1964 & .50 & .11 & .15 & .02 & .01 & .15 & .06 \\
\hline Portugal, 1945-1949 & .54 & .19 & .00 & .10 & .00 & .06 & .10 \\
\hline Portugal, 1960-1964 & .47 & .21 & .00 & .11 & .01 & .06 & .13 \\
\hline Spain, 1945-1949 & .54 & .21 & .01 & .01 & .01 & .06 & .16 \\
\hline Spain, 1960-1964 & .41 & .25 & .05 & .02 & .03 & .08 & .18 \\
\hline Slovenia, 1950-1954 & .58 & .07 & .11 & .03 & .01 & .15 & .06 \\
\hline Slovenia, 1960-1964 & .40 & .08 & .17 & .17 & .04 & .09 & .05 \\
\hline Italy, 1945-1949 & .61 & .21 & .02 & .01 & .00 & .04 & .11 \\
\hline Italy, 1960-1964 & .39 & .25 & .03 & .01 & .03 & .05 & .24 \\
\hline Latvia, 1945-1949 & .44 & .11 & .14 & .03 & .02 & .13 & .13 \\
\hline Latvia, 1960-1964 & .39 & .09 & .18 & .05 & .04 & .18 & .08 \\
\hline Norway, 1945-1949 & .51 & .14 & .07 & .02 & .04 & .14 & .08 \\
\hline Norway, 1955-1959 & .23 & .08 & .27 & .08 & .13 & .13 & .07 \\
\hline Austria, 1945-1949 & .45 & .14 & .10 & .05 & .03 & .16 & .08 \\
\hline Austria, 1960-1964 & .22 & .08 & .25 & .15 & .10 & .12 & .07 \\
\hline Canada, 1945-1949 & .48 & .21 & .02 & .02 & .03 & .12 & .12 \\
\hline Canada, 1960-1964 & .20 & .19 & .11 & .09 & .12 & .15 & .14 \\
\hline USA, 1950-1954 & .29 & .16 & .10 & .06 & .06 & .22 & .11 \\
\hline USA, 1960-1964 & .20 & .13 & .14 & .13 & .08 & .22 & .11 \\
\hline The Netherlands, $1950-1954$ & .42 & .21 & .16 & .02 & .07 & .07 & .07 \\
\hline The Netherlands, 1960-1964 & .18 & .14 & .36 & .05 & .15 & .05 & .08 \\
\hline France, 1945-1949 & .48 & .10 & .09 & .07 & .06 & .10 & .11 \\
\hline France, 1960-1964 & .14 & .06 & .15 & .24 & .14 & .18 & .09 \\
\hline Finland, 1945-1949 & .41 & .15 & .12 & .02 & .05 & .12 & .13 \\
\hline Finland, 1955-1959 & .13 & .05 & .40 & .11 & .15 & .07 & .10 \\
\hline New Zealand, 1945-1949 & .45 & .20 & .06 & .05 & .02 & .13 & .09 \\
\hline New Zealand, 1960-1964 & .12 & .12 & .25 & .18 & .15 & .11 & .08 \\
\hline Estonia, 1945-1949 & .07 & .01 & .21 & .46 & .07 & .07 & .12 \\
\hline Estonia, 1960-1964 & .12 & .01 & .33 & .26 & .06 & .12 & .11 \\
\hline Sweden, 1945-1949 & .14 & .06 & .27 & .23 & .12 & .12 & .06 \\
\hline Sweden, 1955-1959 & .07 & .03 & .18 & .34 & .20 & .10 & .09 \\
\hline
\end{tabular}

Countries are classified by declining proportion of TEM in the youngest birth cohort 
and even rising in popularity, in Mediterranean countries, like Italy, Spain and Portugal. In Canada, The Netherlands and New Zealand it is also relatively popular amongst the oldest cohort, but clearly loses ground amongst younger cohorts. The MLM-template, that combines postponement and premarital cohabitation, is not very popular in most countries, but shows a marked increase in popularity in 15 of the 19 countries in this study. More than $20 \%$ of all respondents from the youngest birth cohort are classified in this template in Norway, Austria, The Netherlands, Finland, New Zealand and Estonia. Sweden is the only country where this template is becoming less popular. The ALM-template, with childbearing within a cohabiting relationship as its most salient characteristic, classifies more than $20 \%$ of all respondents in three countries only. It is popular in France, Estonia and Sweden. In Sweden and France it is the template that includes the largest proportion of respondents amongst the youngest cohort. The SCO-template that focusses on sequential unmarried cohabitation without parenthood, is a relatively unpopular template, but is clearly becoming more important in Norway, Austria, Canada, The Netherlands, France, Finland, New Zealand and Sweden. The PDI-template, characterized by marriage dissolution after entry into motherhood, and thus implying substantial levels of single motherhood, shows little variation across cohorts and countries. At least $5 \%$ of all respondents are classified in this template in all countries, but this proportion is much higher in the USA (22\% in the oldest and the youngest cohort) and Latvia and France (18\% in the youngest cohort in both countries). Finally, the SIN-template, characterized by no family formation at all before age 30, shows a stable picture as well. In most countries, staying single during young adulthood is a pattern followed by between $5 \%$ and $15 \%$ of the respondents. Higher and rising proportions are mainly found in Italy and Spain.

Figure 1 offers a graphical representation of the changes in the distribution of family-life trajectories across cohorts. Each dot represents the change between the

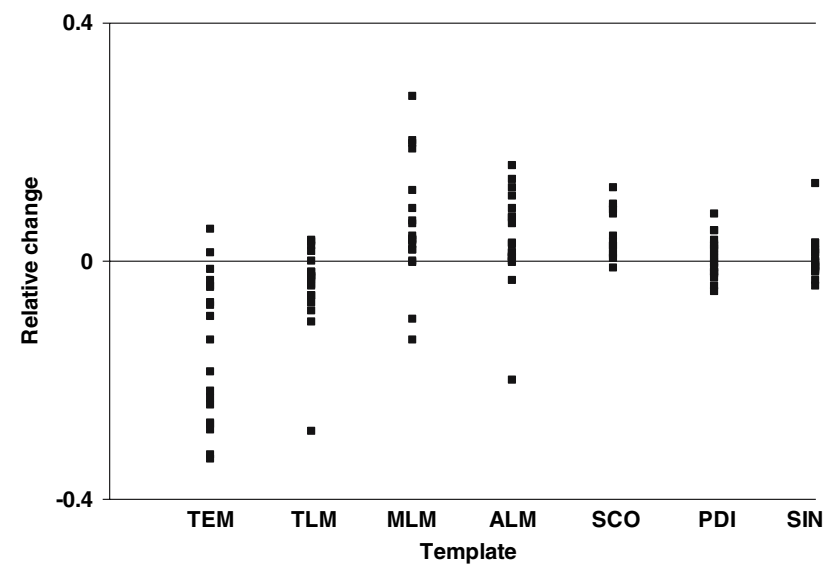

Fig. 1 Changes between the oldest and youngest cohorts in a country in the proportion of women assigned to specific family-life templates 
oldest and the youngest cohort in the proportion of women who are classified in a specific template in a specific country. Positive values imply an increase in the popularity of a specific template, whereas negative values imply a decrease in the popularity of a specific template. Figure 1 shows that the TEM-template has become much less popular. The same is true, though to a lesser extent, for the TLMtemplate. The MLM and ALM, templates that include unmarried cohabitation and postponement of childbearing, have become more popular, as is true for the SCO template. Finally, the proportion of women who follow the PDI- and SIN-templates has not changed much across cohorts in most countries.

Another way of looking at the results in Table 6 is to see what they imply for our understanding of the classification of countries. The clearest results are found for the former Communist countries, with the exception of Estonia. These countries are characterized by a clear dominance of the TEM-template, and relatively little change across cohorts. Estonia is clearly different, because the MLM- and ALMtemplates are very popular in this country, implying that childbearing occurs somewhat later and more often within a consensual union than in other former Communist countries. The Mediterranean countries Italy, Spain and Portugal, resemble the former Communist countries rather closely, with one clear difference. In Spain and Italy - and to a lesser extent in Portugal-union formation and

Table 6 Relative entropy $h$ of the distribution of family-life trajectories across templates (see Table 4) per country and cohort

\begin{tabular}{|c|c|c|c|c|}
\hline & 1945-1949 & 1950-1954 & 1955-1959 & 1960-1964 \\
\hline Poland & 0.598 & 0.583 & 0.621 & \\
\hline Portugal & 0.675 & 0.621 & 0.656 & 0.731 \\
\hline Hungary & & 0.636 & 0.676 & 0.729 \\
\hline Lithuania & 0.668 & 0.718 & 0.712 & 0.733 \\
\hline Czech & & 0.763 & 0.747 & 0.752 \\
\hline Italy & 0.573 & 0.598 & 0.688 & 0.755 \\
\hline Spain & 0.647 & 0.656 & 0.669 & 0.792 \\
\hline Estonia & 0.780 & 0.802 & 0.841 & 0.854 \\
\hline Latvia & 0.828 & 0.844 & 0.820 & 0.857 \\
\hline Slovenia & & 0.684 & 0.768 & 0.859 \\
\hline Sweden & 0.925 & 0.893 & 0.886 & \\
\hline Finland & 0.846 & 0.904 & 0.883 & \\
\hline Netherlands & 0.814 & 0.894 & 0.885 & \\
\hline Norway & 0.766 & 0.881 & 0.936 & \\
\hline Austria & 0.819 & 0.889 & 0.943 & 0.949 \\
\hline France & 0.833 & 0.883 & 0.947 & 0.963 \\
\hline New Zealand & 0.806 & 0.885 & 0.957 & 0.968 \\
\hline USA & & 0.921 & 0.949 & 0.974 \\
\hline Canada & 0.750 & 0.875 & 0.943 & 0.983 \\
\hline
\end{tabular}

Countries are ordered according to the relative entropy of the last cohort available 
motherhood are being postponed, resulting in more respondents being classified in templates TLM and SIN. However, templates that include unmarried cohabitation do not gain in popularity. Differences between countries that can be classified as liberal, conservative and social-democratic, are not very large. In all of these countries, TEM is losing ground, and MLM, ALM and SCO are gaining ground, due to postponement of parenthood and the rising popularity of unmarried cohabitation. Sweden stands out in the sense that it seems to be ahead of the changes in other countries belonging to this group.

It is clear that major shifts in the proportion of women classified into specific templates have occurred across cohorts in many countries. But has this also led to an increase in the variation of different templates, as implied by our variety hypothesis? To examine this issue, we calculated the entropy of the template distributions per country and per cohort. In Table 6, the relative entropy is presented per country and per cohort, and Fig. 2 presents the trends in these results graphically. Apart from Sweden and the Czech Republic, all countries show an increase of relative entropy between the first and last cohorts available and, as clearly shown in Fig. 2, the general trend is one of increasing entropy, i.e., of increasing variation in the types of family formation trajectories. Evidently, our third hypothesis holds for the vast majority of the countries studied.

The results of Table 6 also show clear differences between groupings of countries in their level of relative entropy. In line with our expectations, the variation in family-life trajectories is smallest in the countries that either belong to the class of former Communist countries or belong to the Mediterranean welfareregime type. Contrary to expectations, the level of variation is not highest amongst countries that can be classified as belonging to the Social-Democratic welfareregime type, but rather in countries belonging to the Liberal regime type. Amongst women born between 1960 and 1964 the highest entropy is found in New Zealand, the USA and Canada.

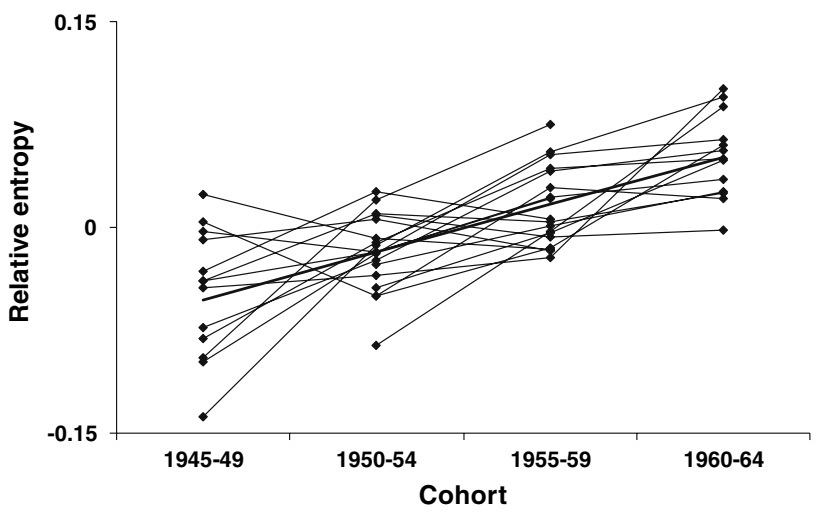

Fig. 2 Displaced graphs of the cross-cohort changes in relative entropy $h$ for 19 countries (numerical data in Table 6). Each graph was vertically displaced by subtracting the country's average relative entropy. The fat line shows the average linear trend with Pearsons's $r^{2}=.55$ 


\section{Discussion}

The aim of this article was to study changes in the family-life trajectories amongst women born between 1945 and 1964 in Western societies. Most theories suggest that the variation in these trajectories has increased as a result of the postponement of marriage and motherhood and the increasing popularity of unmarried cohabitation and union dissolution. We used a number of innovative methods to test a set of hypotheses about the extent and direction of the changes in family-life trajectories.

Our first hypothesis stated that the level of turbulence of family-life trajectories increased across cohorts. By turbulence, we mean not just that the number of family-life events in the transition to adulthood is increasing, but also that the order of states becomes less predictable and that the variance of the durations spent in different states decreases. To test this hypothesis, we used a new indicator that takes all three of these aspects into account. The results show that, contrary to our hypothesis, in the majority of countries the level of turbulence of the family-life trajectories was rather stable, even in countries that are often regarded as frontrunners in demographic change like The Netherlands and Sweden.

The second hypothesis stated that family-life trajectories of women within a country would become more dissimilar across cohorts. We measured the similarity of family-life trajectories by calculating the number of matching subsequences of these trajectories, taking the duration of each position and the frequency of occurrence of different subsequences into account. Strong support for this hypothesis was found. In all countries, except Latvia, Poland, Lithuania and the Czech Republic, a clear increase in dissimilarity of family-life trajectories was observed.

Our third hypothesis stated that the variation in different types of family-life trajectories would increase across cohorts within countries. To study this issue, we constructed seven ideal types of family-life trajectories, called 'templates', calculated the distance between individual trajectories and these templates using the distance measure developed to test the second hypothesis and classified individual trajectories according to their closeness to the seven templates. The results showed that the dominance of one type of family-life trajectory-traditional family formation, characterized by early marriage and motherhood-clearly decreased in countries belonging to the social-democratic, liberal and conservative welfare-regime type, but that this was much less the case in Mediterranean and former Communist countries. At the same time, several other types of trajectories, in particular Traditional Late Motherhood-characterized by postponed marriage and motherhood-, Modern Late Motherhood-characterized by a spell of unmarried cohabitation before marriage-and Alternative Late Motherhoodcharacterized by parenthood within a consensual union rather than within marriage-were all becoming more common amongst young adults. Taken together, a clear increase in variation in the types of templates was observed in all countries, except in Sweden, the Czech Republic and, to a lesser extent, The Netherlands.

These results offer strong support to the idea that the family-life trajectories of young adult women all across the Western world are becoming more de-standardized. Trajectories are becoming more dissimilar and the variation in 
the types of trajectories is increasing. At the same time, some interesting additional conclusions can be drawn. First, the rejection of our turbulence hypothesis shows that an increase in the variation of trajectories between individuals does not necessarily imply that the average trajectory itself becomes more turbulent as well. To put it differently; amongst younger cohorts, individual family-life trajectories are not much more eventful, but there is a much stronger variation between individuals in what exact events actually occur. Second, the decrease in variation in family-life trajectories observed in Sweden and, to a lesser extent, also in the Netherlands, suggests that new standards may be emerging in these countries. In that sense, it is not impossible that a process of re-standardization will occur in countries that have experienced the Second Demographic Transition.

The fourth hypothesis suggested that de-standardization would have progressed furthest in countries characterized by a social-democratic welfare-state regime, followed by countries characterized by a liberal or a conservative welfare-state regime. Former Communist countries and Mediterranean countries were expected to show the least de-standardization. The results partly confirmed our expectations, but quite clear deviations from expectations were observed as well. In line with expectations, former Communist countries showed little turbulence and little destandardization. In addition, hardly any increase in turbulence and dissimilarity of family-life trajectories was observed, suggesting that family formation in the Communist era was strongly standardized. Estonia was the only clear exception to this picture, probably due to the wide diffusion of living in a consensual union, even in the Communist era. Little turbulence and de-standardization was also found in Mediterranean countries, but—contrary to what was observed in former Communist countries - some cross-cohort changes were observed. In Spain and Italy a clear postponement of marriage and motherhood was visible. Not only was the proportion of young adult women characterized by late motherhood increasing, the same was true for the proportion of women characterized by the postponement of union formation until after age 30. The small difference between countries belonging to the social-democratic, liberal and conservative welfare-regime types is probably the most surprising result of all. Scandinavian countries did not stand out with regard to turbulence, dissimilarity or template type. Although Sweden clearly confirmed its reputation as one of the countries leading demographic change, Norway and Finland showed patterns that were observed in many countries of the conservative and liberal welfare-regime types as well. A final surprising fact is that the USA was clearly one of the most de-standardized countries of all. It topped the board with regard to dissimilarity, also showed high turbulence, and its template distribution was rather uncharacteristic. It seems that it was the widespread occurrence of out-of wedlock childbearing, in combination with a relatively high rate of union dissolution, even in the presence of children, that made the USA one of the most de-standardized countries in the Western world.

Methodologically, this article introduced a number of new methods to study trajectories in a holistic fashion. We think that the results of the substantive analyses attest to the usefulness of these methods. What makes them particularly attractive is that, in contrast to most other methods to analyze sequences, these methods incorporate the duration of states in a substantively meaningful and verifiable way. 
At the same time, a number of limitations of our study should be mentioned. First, there are obvious limitations that arise from the nature of the data. Retrospective data inevitably suffer from inaccuracy and incompleteness, all the more so amongst older cohorts. So, de-standardization may be underestimated amongst older cohorts since these cohorts will remember fewer events and probably tend to underreport short spells of any nature. Furthermore, the data limit our view on family-life trajectories since trajectories are not observed after age 30: substantial levels of de-standardization might occur beyond that age. Finally, some types of living arrangements do not appear in our state space, with underestimation of entropy as a result. For example, amongst younger cohorts couples may live together part time, i.e., live together for a limited number of days per week. Another example is part-time parenthood: shared childcare by different households.

Second, biasses and limitations might arise from our choices of method. Ideally, the choice of a specific method should be guided by a well-articulated scientific theory. However, theories about demographic change are usually rather 'fuzzy' and do not lead to clear-cut operational decisions. As a result, we made a number of methodological decisions that could be disputed. So, although we feel that we have good arguments to propose our measure of turbulence, it is just one of many possible operationalizations. Next, we used the number of matching subsequences $m(x, y)$ as the building block of both distance (Eq. 4) and similarity (Eq. 5). Again, this is an arbitrary choice although we feel it is well defendable in social science applications. At the same time, we know that it is possible to construct other Euclidean and non-Euclidean metrics. Interestingly, Brüderl (2004), using the OM-metric and a slightly more restricted state space, found increasing de-standardization amongst young male and female West-Germans. Our results on increased variation in the kinds of trajectories certainly depend upon the choice of the templates: with different templates we would probably have found different distributions. Furthermore, it is not clear that the templates characterize the clusters that are constructed with them: templates may well have a relatively peripheral spatial position in their own cluster. Finally, our choice to use entropy to describe probabilistic variation is arbitrary; we might just as well have chosen Gini's index (Gini 1921) or some other coefficient.

These limitations notwithstanding, we feel that the methods introduced in this article lead to interesting results. Moreover, the applications presented here do not exhaust these methods' possibilities. For instance, researchers interested in studying the factors that influence the level of turbulence of family-life trajectories could use the turbulence indicator as a dependent variable in a regression model. Furthermore, these methods could also be used to study the consequences of disorder in the life course (Rindfuss et al. 1987), by calculating the turbulence or the distance between an individual's family-life trajectory and some predetermined template and using this as a dependent variable predicting well-being or socio-economic achievement. Finally, there is no reason to limit the applicability of these methods to family-life trajectories during young adulthood. They could also be used to study these trajectories over a longer period of a person's life, or to study trajectories that include a larger number of states, either in the family-life domain or in several different life-domains at the same time. 
Acknowledgement The authors thank the participants at the IUSSP Workshop on Transitions to Adulthood, held at the Université de Montréal, Canada, and the anonymous reviewers for their stimulating comments. They also wish to thank the Advisory Group of the FFS programme of Comparative Research for its permission (granted under identification 41) to use the FFS data on which this study is based.

\section{References}

Abbott, A. (1984). Event sequence and event duration: Colligation and measurement. Historical Methods, 17, 192-204.

Abbott, A., \& Tsay, A. (2000). Sequence analysis and optimal matching methods in sociology: Review and prospect. Sociological Methods \& Research, 29, 3-33.

Arnett, J. J. (2000). Emerging adulthood. A theory of development from the late teens through the twenties. American Psychologist, 55, 469-480.

Beck, U., \& Beck-Gernsheim, E. (1996). Individualization and 'Precarious Freedoms': Perspectives and controversies of a subject-orientated sociology. In P. Heelas, S. Lash, \& P. Morris (Eds.), Detraditionalization. Critical reflections on authority and identity (pp. 23-48). Cambridge: Blackwell Publishers.

Billari, F. C., \& Piccarreta, R. (2005). Analysing demographic life courses through sequence analysis. Mathematical Population Studies, 12, 81-106.

Brückner, H., \& Mayer, K. U. (2005). De-standardization of the life course: What might it mean? And if it means anything, whether it actually took place. In R. Macmillan (Ed.), The structure of the life course: Standardized? Individualized? Differentiated? (Advances in Life Course Research, Volume 9) (pp. 27-53). Amsterdam: Elsevier.

Brüderl, J. (2004). Die Pluralisierung partnerschaftlicher Lebensformen in Westdeutschland und Europa. Aus Politik und Zeitgeschichte, B19, 3-10.

Brüderl, J., \& Scherer, S. (2006). Methoden zur Analyse von Sequenzdaten. In A. Diekmann (Ed.), Methoden der Sozialforschung. Special issue 44 of the Kölner Zeitschrift für Soziologie und Sozialpsychology (pp. 330-347). Wiesbaden: VS-Verlag.

Brzinsky-Fay C. (2006). Lost in transition: Labour market entry sequences of school leavers in Europe (pp. 2006-111). Berlin: Wissenschaftszentrum Berlin für Sozialforschung (WZB), SP I.

Buchmann, M. (1989). The script of life in modern society. Entry into adulthood in a changing world. Chicago, Ill: University of Chicago Press.

Corijn, M., \& Klijzing, E. (2001). Transitions to adulthood in Europe. Dordrecht: Kluwer.

Cover, T., \& Thomas, J. (1991). Elements of information theory. New York: Wiley.

Davison, A. C., \& Hinkley, D. V. (1997). Bootstrap methods and their application (Cambridge Series in Statistical and Probabilistic Mathematics, No. 1). Cambridge: Cambridge University Press.

Dijkstra, W., \& Taris, T. (1995). Measuring the agreement between sequences. Sociological Methods \& Research, 24, 214-231.

Efron, B., \& Tibshirani, R. J. (1994). An Introduction to the bootstrap. Boca Raton (Flor.): Chapman \& Hall/CRC.

Elzinga, C. H. (2003). Sequence similarity-a non-aligning technique. Sociological Methods \& Research, 31, 3-29.

Elzinga, C. H. (2005). Combinatorial representation of token sequences. Journal of Classification, 21(1), 87-118.

Elzinga, C. H. (2006). Turbulence in categorical time series (submitted).

Esping-Andersen, G. (1990). Three worlds of welfare capitalism. Cambridge: Polity Press.

Esping-Andersen, G. (1999). Social foundations of postindustrial economies. Oxford: Oxford University Press.

Festy, P., \& Prioux, F. (2002). An evaluation of the fertility and family surveys project. New York: United Nations.

Fussell, E. (2005). Measuring the early adult life course in Mexico: An application of the entropy index. In R. Macmillan (Ed.), The structure of the life course: Standardized? Individualized? Differentiated? (Advances in Life Course Research, Volume 9) (pp. 91-122). Amsterdam: Elsevier.

Fussell, E., \& Gauthier, A. H. (2005). American women's transition to adulthood in comparative perspective. In R. A. Settersten, F. F. Furstenberg Jr., \& R. G. Rumbaut (Eds.), On the frontier 
of adulthood: Theory, research and public policy (pp. 76-109). Chicago: University of Chicago Press.

Gelissen, J. (2001). Worlds of welfare, worlds of consent? Public opinion on the welfare state. Amsterdam: Thela Thesis.

Gini, C. (1921). Measurement of inequality and incomes. The Economic Journal, 31, 124-126.

Goldscheider, F. K. (1997). Recent changes in U. S. young adults living arrangements in comparative perspective. Journal of Family Issues, 18, 708-724.

Hartigan J. (1975). Clustering algorithms. New York: Wiley.

Lesthaeghe, R. (1995). The second demographic transition western countries: An interpretation. In K. O. Mason \& A.-M. Jensen (Eds.), Gender and family change in industrialized countries (pp. 17-62). Oxford: Clarendon Press.

Lesthaeghe, R., \& Van de Kaa, D. J. (1986). Twee demografische transities? In D. J. Van de Kaa \& R. Lesthaeghe (Eds.), Bevolking: Groei en Krimp (pp. 9-24). Deventer: Van Loghum Slaterus.

Lesthaeghe, R., \& Willems, P. (1999). Is low fertility a temporary phenomenon in the European union? Population and Development Review, 25, 211-228.

Liefbroer, A. C. T., \& Goldscheider, F. (2006). Transitions to adulthood: How unique is Sweden the European context? In E. M. Bernhardt, C. Goldscheider, F. Goldscheider, \& G. Bjerén (Eds.), Immigration, gender and family transitions to adulthood in Sweden. Lanham, MD: University Press of America.

Liefbroer A. C., \& Jong Gierveld, J. de (1995). Standardization and individualization: The transition from youth to adulthood among cohorts born between 1903 and 1965. In J. C. van den Brekel \& F. Deven (Eds.), Population and family in the low countries 1994 (pp. 57-80). Dordrecht: Kluwer Academic Publishers.

Milligan, G. W., \& Cooper, M. C. (1985). An examination of procedures for determining the number of clusters in a data set. Psychometrika, 50, 159-179.

Mills, M. (2004). Stability and change: The structuration of partnership histories in Canada, The Netherlands and the Russian Federation. European Journal of Population, 20, 141-175.

Mouw, T. (2005). Sequences of early adult transitions: A look at variability and consequences. In R. A. Settersten, F. F. Furstenberg Jr., \& R. G. Rumbaut (Eds.), On the frontier of adulthood: Theory, research and public policy (pp. 256-291). Chicago: University of Chicago Press.

Piccarreta, R. (1998). Divisive monothetic algorithms for clustering binary data: A proposal. In Proceedings of the NTTS '98 International Seminar, Sorrento (pp. 405-410).

Rindfuss, R. C., Swicegood, C. G., \& Rosenfeld, R. A. (1987). Disorder in the life course: How common and does it matter? American Sociological Review, 52, 785-801.

Settersten, R. A., \& Mayer, K. A. (1997). The measurement of age, age structuring, and the life course. Annual Review of Sociology, 23, 233-261.

Shanahan, M. J. (2000). Pathways to adulthood: Variability and mechanisms in life course perspective. Annual Review of Sociology, 26, 667-692.

Tibshirani, R., Walther, G., \& Hastie, T. (2002). Estimating the number of clusters in a data set via the gap statistic. Journal of the Royal Statistical Society, Series B, 63(2), 411-423.

Van de Kaa, D. J. (1987). Europe's second demographic transition. Population Bulletin, 42(1), whole issue.

Van de Kaa, D. J. (1994). The second demographic transition revisited: Theories and expectations. In G. C. N. Beets et al. (Eds.), Population and Family in the low countries 1993: Late fertility and other current issues. Lisse: Swets and Zeitlinger.

Van de Kaa, D. J. (2001). Postmodern fertility preferences: From changing value orientations to new behavior. In R. A. Bulatao \& J. B. Casterline (Eds.), Global fertility transition (pp. 290-331). New York: Population Council.

Wu, L. L. (2000). Some comments on "sequence analysis and optimal matching in sociology: Prospect and review". Sociological Methods \& Research, 29(1), 41-64.

Wu, L. L., \& Li, J.-C. A. (2005). Historical roots of family diversity. In A. R. Settersten, F. F. Furstenberg, \& R. G. Rumbaut (Eds.), On the frontier of adulthood: Theory, research and public policy (pp. 110-149). Chicago: The University of Chicago Press. 